medRxiv preprint doi: https://doi.org/10.1101/2021.07.26.21261157; this version posted July 29, 2021. The copyright holder for this preprint (which was not certified by peer review) is the author/funder, who has granted medRxiv a license to display the preprint in perpetuity. It is made available under a CC-BY-NC-ND 4.0 International license .

\title{
Whole-genome sequencing analysis of clozapine-induced myocarditis
}

Running title: Genome analysis of clozapine-induced myocarditis

Ankita Narang ${ }^{1}$, Paul Lacaze ${ }^{2}$, Kathlyn J Ronaldson ${ }^{2}$, John J McNeil ${ }^{2}$, Mahesh Jayaram ${ }^{3,4}$, Naveen Thomas $^{3,4}$, Rory Sellmer $^{5}$, David Crockford ${ }^{5}$, Robert Stowe ${ }^{6}$, Steven C. Greenway ${ }^{7,8,9,10,11}$, Christos Pantelis ${ }^{3,4}$, Chad A Bousman ${ }^{1,5,9,12,13}$

${ }^{1}$ Department of Medical Genetics, University of Calgary, Calgary, AB, Canada.

${ }^{2}$ Department of Epidemiology and Preventive Medicine, Monash University, Melbourne, VIC, Australia

${ }^{3}$ Adult Mental Health Rehabilitation Unit, North Western Mental Health, Melbourne Health, Western Health, Sunshine Hospital, St Albans, VIC, Australia

${ }^{4}$ Melbourne Neuropsychiatry Centre, Department of Psychiatry, The University of Melbourne and Melbourne Health, Western Centre for Health \& Education, St Albans, VIC, Australia

${ }^{5}$ Department of Psychiatry, University of Calgary, Calgary, AB, Canada

${ }^{6}$ Departments of Psychiatry and Neurology (Medicine), Neuropsychiatry Program, and Djavad Mowafaghian Centre for Brain Health, University of British Columbia, Vancouver, BC, Canada

${ }^{7}$ Department of Pediatrics, Cumming School of Medicine, University of Calgary, Calgary, AB, Canada

${ }^{8}$ Department of Biochemistry \& Molecular Biology, Cumming School of Medicine, University of Calgary, Calgary, AB, Canada

${ }^{9}$ Alberta Children's Hospital Research Institute, Cumming School of Medicine, University of Calgary, Calgary, AB, Canada

${ }^{10}$ Department of Cardiac Sciences, Cumming School of Medicine, University of Calgary, Calgary, AB, Canada

${ }^{11}$ Libin Cardiovascular Institute, Cumming School of Medicine, University of Calgary, Calgary, AB, Canada

${ }^{12}$ Department of Physiology \& Pharmacology, University of Calgary, Calgary, AB, Canada.

${ }^{13}$ Hotchkiss Brain Institute, Cumming School of Medicine, University of Calgary, Calgary, AB, Canada

Correspondence: Chad Bousman, Department of Medical Genetics, University of Calgary, 270 HMRB, 3330 Hospital Drive NW, Calgary, AB T2N 4N1, Canada. Tel: +1 403210 7273; e-mail: chad.bousman@ucalagary.ca 
medRxiv preprint doi: https://doi.org/10.1101/2021.07.26.21261157; this version posted July 29, 2021. The copyright holder for this preprint (which was not certified by peer review) is the author/funder, who has granted medRxiv a license to display the preprint in perpetuity. It is made available under a CC-BY-NC-ND 4.0 International license .

\section{ABSTRACT}

40 One of the concerns limiting the use of clozapine in schizophrenia treatment is the risk of rare but potentially fatal myocarditis. Our previous genome-wide association study and human leucocyte antigen analyses identified putative loci associated with clozapine-induced myocarditis. However, the contribution of DNA variation in cytochrome P450 genes, copy number variants and rare deleterious variants have not been investigated. We explored these unexplored classes of DNA variation using whole-genome sequencing data from 25 cases with clozapine-induced myocarditis and 25 demographically-matched clozapine-tolerant control subjects. We identified 15 genes based on rare variant gene-burden analysis (MLLT6, CADPS, TACC2, L3MBTL4, NPY, SLC25A21, PARVB, GPR179, ACAD9, NOL8, C5orf33, FAM127A, AFDN, SLC6A11, PXDN) nominally associated $(\mathrm{p}<0.05)$ with clozapine-induced myocarditis. Of these genes, 13 were expressed in human myocardial tissue. Although independent replication of these findings is required, our study provides preliminary insights into the potential role of rare genetic variants in susceptibility to clozapine-induced myocarditis. 
medRxiv preprint doi: https://doi.org/10.1101/2021.07.26.21261157; this version posted July 29, 2021. The copyright holder for this preprint (which was not certified by peer review) is the author/funder, who has granted medRxiv a license to display the preprint in perpetuity. It is made available under a CC-BY-NC-ND 4.0 International license .

\section{INTRODUCTON}

Clozapine initiation for patients suffering from treatment-resistant schizophrenia is recommended at the earliest possible opportunity by clinical guidelines, ${ }^{1,2}$ and there is evidence for its superior efficacy in this difficult-to-treat population compared with other pharmacological treatments ${ }^{3}$. Regulatory requirements around serious adverse event monitoring have largely addressed the risk of undiagnosed agranulocytosis. However, there has been ongoing concern about a serious idiosyncratic adverse drug reaction (ADR) involving inflammation of the myocardium.

In 1999, Kilian and colleagues ${ }^{4}$ reported the rate of myocarditis (both fatal and non-fatal) as 1.9 per 1000 patients starting clozapine. However, more recent projections suggest rates as high as $3 \%$ in the context of systematic monitoring, with fatality rates ranging from $7 \%$ to $75 \%{ }^{5}$. Despite these alarming rates, our current ability to identify those at greatest risk for clozapine-induced myocarditis is inadequate. This uncertainty has led to reduced clozapine prescription and arguably poorer patient outcomes. Although research to uncover risk factors has identified a few clinical markers ${ }^{6,7}$, these factors do not account for all the risk. As such, identification of additional markers is needed to reduce or prevent fatalities and morbidity resulting from clozapine-induced myocarditis, potentially facilitating expanded and safer use of this highly effective medication.

Genomic analysis is a promising and largely unexplored approach for identifying those at risk of idiosyncratic ADRs. In fact, our recent genome-wide association study (GWAS) and human leucocyte antigen (HLA) analyses of clozapine-induced myocarditis identified four independent loci (SIX3, EFHC1, ADAM7, and GNA15) suggestive of increased myocarditis risk $\left(\mathrm{P}<1 \times 10^{-6}\right)$, with odds ratios ranging from 5.5 to 13.7. We also found that the HLA-C*07:01 allele was associated with 2.89-fold (95\% CI: 1.11-7.53) greater odds of clozapine-induced myocarditis ${ }^{8}$. To build on these promising findings, we undertook the first whole-genome sequencing study to examine different classes of DNA variation not measured in our previous genetic study, including rare deleterious coding variants, copy number variants, and candidate variation in pharmacogenes associated with clozapine metabolism. Herein, we report our results among a cohort of individuals with and without a history of clozapine-induced myocarditis, in collaboration with members of the Pharmacogenomics of Clozapine-Induced Myocarditis (PROCLAIM) Consortium? 9 
medRxiv preprint doi: https://doi.org/10.1101/2021.07.26.21261157; this version posted July 29, 2021. The copyright holder for this preprint

\section{METHODS}

\section{Study Participants}

Participants with $(n=25)$ and without $(n=25)$ a history of clozapine-induced myocarditis were recruited by investigators affiliated with the PROCLAIM Consortium at the University of Calgary, University of Melbourne, and Monash University. For this study, we included 34 participants (19 cases and 19 controls) included in our previous GWAS study ${ }^{8}$. For each recruited case of clozapine-induced myocarditis, an age ( \pm 5 years), sex, and ancestry-matched clozapine-tolerant control was recruited from the same site. Genetic ancestry of controls and cases was further assessed by principal component analysis using the smartpca module of the EIGENSOFT package (Supplementary Figure S1). Individuals were eligible for inclusion into the study if they: (a) were aged 18 to 65 years, (b) had a clinical diagnosis of a schizophrenia-spectrum disorder, (c) had accessible medical records, and (d) had a history of clozapine therapy. For cases, an additional inclusion criterion was a history of myocarditis evidenced by abnormal troponin I/T levels ( $>2$ times upper limit of normal) or signs of left ventricular dysfunction with or without elevated C-reactive protein (CRP) levels (>100mg/L) during the first 30 days of clozapine therapy, which aligns with current monitoring guidelines ${ }^{10}$. An additional inclusion criterion for clozapine-tolerant controls was evidence of clozapine therapy for a minimum of 45 days with no documented history or clinical suspicion of myocarditis. The present study was approved by the Melbourne Health Human Research Ethics Committee and University of Calgary Conjoint Health and Research Ethics Board. The study also complied with the Declaration of Helsinki and its subsequent revisions. All participants or next of kin provided written informed consent prior to participation.

\section{Whole genome sequencing}

Genomic DNA (750 - $1000 \mathrm{ng}, \mathrm{A}_{260} / \mathrm{A}_{280}$ ratio > 1.8) was isolated from whole blood samples using standard procedures and shipped to the Centre for Applied Genomics at the Hospital for Sick Children

112 (Toronto, Canada) for library preparation and sequencing. Libraries were prepared for all samples using the Illumina TruSeq PCR-free DNA library preparation kit. Each library was subjected to 150 base, paired end sequencing on three lanes of the Illumina HiSeqX.

The Illumina DRAGEN (version 07.021.382.3.4.9, Dynamic Read Analysis for GENomics) 
medRxiv preprint doi: https://doi.org/10.1101/2021.07.26.21261157; this version posted July 29, 2021. The copyright holder for this preprint (which was not certified by peer review) is the author/funder, who has granted medRxiv a license to display the preprint in perpetuity. It is made available under a CC-BY-NC-ND 4.0 International license .

117 alignment, sorting and duplicate marking was performed to generate aligned BAM files. Next, sample118 wise gVCF files were generated using DRAGEN's haplotype calling algorithm and then these files were run through the joint calling algorithm to generate a joint VCF file. dbSNP (v150) was used to annotate variants. The jointly called VCF file was further recalibrated using the Variant Quality Score Recalibration (VQSR) algorithm to produce a high-quality variant dataset. The VQSR model was trained for single nucleotide polymorphisms (SNPs) and insertion/deletions (indels) using high quality variant data from different resources (see Supplementary Methods for more details). For SNPs, the VQSR model was trained using data from HapMap3.3, 1000 Genomes Project (Phase 1 SNP sites and Omni 2.5 M SNP array) and dbSNP (v150), with a sensitivity threshold of $99.5 \%$. For indels, the VQSR was trained using data in the 1000 Genomes Project (gold standard sites) and Illumina Platinum sites, with a sensitivity threshold of $99.0 \%$. Only "PASS" calls were annotated using ANNOVAR after VQSR implementation.

\section{Pharmacogenetic variant analysis}

131 The Stargazer v1.08 ${ }^{11}$ tool was used to call diplotypes, calculate activity scores, and assign genotypeinferred metabolizer phenotypes for seven genes (CYP1A2, CYP2C9, CYP2C19, CYP2D6, CYP3A4, CYP3A5, CYP2E1) relevant to clozapine metabolism ${ }^{12}$. Stargazer uses whole genome sequencing data to find phased haplotypes comprised of SNPs, small indels, and large structural variants, and then maps these haplotypes to star alleles based on translation tables maintained by the Pharmcogene Variation Consortium $^{13}$. Notably, previous work has shown Stargazer recalled $100 \%$ of star alleles present in the Genetic Testing Reference Material Coordination Program's consensus genotypes ${ }^{11}$. Furthermore, a comparison of Stargazer-predicted diplotypes for the seven target pharmcogenes with the diplotypes generated by the PharmacoScan Solution (Thermofisher, Carlsbad, USA) array in a subset of our sample $(n=22)$ tested on both platforms found high diplotype $(94.8 \%)$ and phenotype (98.1\%) concordance (Supplementary Table S1).

Prior to analysis, activity scores for the seven target pharmacogenes were corrected for concomitant inhibitors or inducers (Supplementary Table S2) using a method previously described ${ }^{14}$. In brief, activity scores for one or more of the seven genes were multiplied by zero if a strong inhibitor of the corresponding enzyme was present. For moderate inhibitors the activity score was multiplied by 0.5 and for inducers the activity score was multiplied by 1.5. In cases where both an inhibitor and 
medRxiv preprint doi: https://doi.org/10.1101/2021.07.26.21261157; this version posted July 29, 2021. The copyright holder for this preprint (which was not certified by peer review) is the author/funder, who has granted medRxiv a license to display the preprint in perpetuity. It is made available under a CC-BY-NC-ND 4.0 International license .

148 was retained, as consensus on how to correct activity scores in this situation has not been established.

149 The corrected activity scores were then used to assign a corrected metabolizer phenotype for each of 150 the seven target genes. To determine differences in activity scores and metabolizer phenotypes 151 between the cases and controls, we used the Mann-Whitney $\mathrm{U}$ and chi-square tests, respectively. $\mathrm{P}$ 152 values were corrected for multiple testing using the Benjamini-Hochberg (B-H) step-up procedure ${ }^{15}$.

\section{Copy number variant (CNV) analysis}

155 CNVs (variants with length $\geq 1 \mathrm{~kb}$ ) were called using the DRAGEN algorithm and self-normalization method. A merged CNV file was created by compiling copy number state and segmentation mean values for all samples. Segmentation mean values were log transformed to construct copy number variable regions (CNVRs). Ten regions where segmentation mean and log transformed segmentation values had conflicting CNV status were excluded (Supplementary Table S3). We used two different tools - CNVRuler ${ }^{16}$ and $\mathrm{CoNVaQ}^{17}$ to construct CNVRs and perform CNVR association analyses. Using CNVRuler, logistic regression was performed using the first two principal components as covariates, and a minor allele frequency threshold of greater than 0.1. CNVRuler performs multiple testing using the B-H step-up procedure ${ }^{15}$. CNVR association analysis was also performed using CoNVaQ with permutation $(n=4000)$ testing by swapping phenotype labels. CNVR encompassing genes were retrieved from the UCSC Genome Browser.

\section{Gene burden analysis and functional annotation of candidate genes}

We performed burden analysis using rare and deleterious variants, defined based on the minor allele frequency from global databases and combined annotation dependent depletion (CADD) annotation score using ANNOVAR software ${ }^{18}$. A variant was considered rare if the maximum allele frequency was less than 0.05 in the 1000 Genomes Project ${ }^{19}$, ESP6500 ${ }^{20}$, ExAC $^{21}, \mathrm{CG}^{22}$ or gnomAD databases $^{23}$. A deleterious variant was defined by a CADD Phred score greater than 20. We used

173 CADD scores to include functionally important variants from protein-coding and non-coding regions.

174 Variants that met both criteria were extracted using BCFtools (v1.9) ${ }^{24}$ and burden analysis was 175 performed on these selected variants. Two different methods were used - Combined and 176 Multivariate Collapsing (CMC) and the sequencing kernel association test (SKAT-O), both 177 implemented in RVTESTS ${ }^{25}$. Permutation analysis (10,000 iterations) was carried out in $\mathrm{R}$ by 178 permuting phenotype labels (case and control) of observations (i.e. total allele counts) to derive 
medRxiv preprint doi: https://doi.org/10.1101/2021.07.26.21261157; this version posted July 29, 2021. The copyright holder for this preprint

179 empirical p-values. We also used TRAPD (Testing Rare vAriants using Public Data) ${ }^{26}$ software to 180 compute the frequency of rare and deleterious alleles of prioritised genes using genome data from 18115,708 individuals in the gnomAD v2 database (build hg19) ${ }^{23}$ and then compared these frequencies 182 with those observed in our cases and controls using a two proportion Z-test. P-values were corrected 183 using the Bonferroni method.

184 To evaluate the tolerance of genes for functional genetic variation, Residual Variation 185 Intolerance Score (RVIS) scores were fetched using the web-based tool Gene Intolerance ${ }^{27}$. RVIS 186 scores are used to rank genes in terms of their functional tolerance ${ }^{28}$. Genes with negative scores 187 represent less tolerance to functional variations. Gene enrichment analysis was performed using 188 ToppFun $^{29}$. Finally, we assessed the mRNA expression of candidate genes in left ventricular-septal 189 tissue from 21 healthy adult donors using published RNASeq data ${ }^{30}$. Raw RNASeq data was retrieved 190 from the Zenodo Data repository ${ }^{31}$. Raw read counts were normalized with DESeq2, using the median 191 of ratios method ${ }^{32}$.

\section{RESULTS}

A summary of the study design and key results are shown in Figure 1.

\section{Study participants and sequencing}

198 Participant characteristics and relevant clinical information for the two patient groups are shown in

199 Table 1. Cases and controls did not differ significantly in their demographic or clinical characteristics, with the exception of titration slope. On average, cases received a faster titration than controls $(\mathrm{p}=$ 0.006). However, post hoc comparisons of case and control titration slopes with those recommended in titration protocols used in $\mathrm{Canada}^{33}$, Australia ${ }^{34}$, and United Kingdom ${ }^{35}$ showed that neither case nor control slopes differed from these national recommendations (Figure 2). In addition, post hoc examination showed no difference in titration slopes by ancestry (Supplementary Figure S2).

One of the control samples failed initial quality assessment post-sequencing, resulting in 25 cases and 24 controls available for further analysis with an average depth of reads and average read mapping across the samples of 33.65x and 92.9\%, respectively (Supplementary Figure S3). Ti/Tv (transition/transversion) ratio for both raw (2.00) and filtered (2.02) calls were in the acceptable whole genome range. On average, there were 3,833,700 SNPs, 953,459 indels and $619 \mathrm{CNV}$ ser individual 
medRxiv preprint doi: https://doi.org/10.1101/2021.07.26.21261157; this version posted July 29, 2021. The copyright holder for this preprint (which was not certified by peer review) is the author/funder, who has granted medRxiv a license to display the preprint in perpetuity. It is made available under a CC-BY-NC-ND 4.0 International license .

210 (Supplementary Table S4). The final jointly called dataset contained 16,014,407 variants (both SNPs 211 and indels).

\section{Pharmacogenetic variants}

215 Observed diplotype frequencies for the seven targeted pharmacogenes, along with the corresponding 216 uncorrected activity scores and genotype-inferred metabolizer phenotypes among cases and controls, 217 are shown in Supplementary Table S5. No significant differences in uncorrected or corrected activity 218 scores were found between cases and controls (Supplementary Table S6) nor were differences detected 219 in the distribution of genotype-inferred metabolizer phenotypes (Supplementary Table S7). 220 Furthermore, titration slopes were not correlated with activity scores for the seven targeted pharmacogenes in cases or controls (Supplementary Table S8). Importantly, post hoc gene burden analysis did not reveal any differences in enrichment of rare and deleterious variants in the seven genes (CYP1A2, CYP2C9, CYP2C19, CYP2D6, CYP3A4, CYP3A5, CYP2E1) known to be involved in clozapine metabolism.

\section{Copy number variants}

We identified 30,340 CNVs across the 49 samples. Comparing the average number of CNVs between cases and controls revealed no statistically significant differences in losses (cases: mean $=498, \pm$ standard deviation $=28$; controls: $503 \pm 19, \mathrm{p}=0.42$ ) or gains (cases: $102 \pm 10$ vs. controls: $117 \pm 8, \mathrm{p}$ $=0.26)$ (Supplementary Table S9). We also did not detect significant differences with respect to the average size of the losses (cases: $10.54 \pm 61.6 \mathrm{~kb}$ vs. controls: $10.57 \pm 59.5 \mathrm{~kb}, \mathrm{p}=0.97$ ) or gains (cases: mean $141.37 \mathrm{~kb}$, sd $=721.9 \mathrm{~kb}$; controls: mean $=134.01 \mathrm{~kb}, \mathrm{sd}=533.5 \mathrm{~kb}, \mathrm{p}=0.66$ ) (Supplementary Table S9). The CNVRuler constructed 3,178 copy number variable regions (CNVRs) among which five were found to be significant ( $\mathrm{p}<0.01$, Supplementary Table S10), while the CoNVaQ tool resulted in ten significant CNVRs ( $\mathrm{p}<0.01$, Supplementary Table S11). However, no CNVR survived permutation analysis or correction for multiple testing.

\section{Rare and deleterious single nucleotide variants}

A total of 22,703 rare and deleterious variants from 8,442 genes (out of 22,480 genic regions scanned) met criteria for gene burden analysis. On average, cases and controls had $739 \pm 51$, and $735 \pm 52$ rare 
medRxiv preprint doi: https://doi.org/10.1101/2021.07.26.21261157; this version posted July 29, 2021. The copyright holder for this preprint

and deleterious variants per sample, respectively $(\mathrm{p}=0.779)$. We identified 114 and 44 genes $(\mathrm{p}<$

242 0.05) using CMC and SKAT-O, respectively and selected 42 common genes for prioritization analysis

243 (Supplementary Figure S4). Out of 42 genes, 15 genes had a rare and deleterious variant in our cohort

244 (Table 2). All genes survive permutation analysis with MLLT6 as the top candidate $\left(\mathrm{p}=4.2 \times 10^{-3}\right)$ but

245 no gene survived multiple testing correction. However, compared to the frequencies of rare and 246 deleterious variants in the gnomAD cohort, cases had significantly greater frequencies for seven 247 (MLLT6, CADPS, TACC2, L3MBTL4, NOL8, FAM172A, AFDN) of the 15 candidate genes, after 248 Bonferroni correction (Table 2). Frequencies in controls did not differ from those observed in the gnomAD cohort for any of the 15 genes.

Gene intolerance analysis showed CADPS, AFDN, and MLLT6 were the most intolerant to rare and deleterious variation, respectively ranking amongst the $2^{\text {nd }}, 5^{\text {th }}$, and $6^{\text {th }}$ percentile of the most intolerant genes. Gene enrichment analysis of the 15 nominally significant genes revealed no significant functional category or pathway. Likewise, gene enrichment analysis including of the 15 nominally significant genes and the four candidate genes from our previous GWAS (i.e, SIX3, EFHC1, $A D A M 7, G N A 15)$ revealed no significant functional category or pathway. However, all 15 genes, with the exception of GPR179 and SLC6A11, were expressed in left ventricular septal tissue from healthy human adult donors with TACC2 and MLLT6 having the highest expression (Figure 3). Among the GWAS candidates, only $S I X 3, E F H C 1$, and GNA15 were expressed in left ventricular septal tissue (Supplementary Figure S5).

\section{DISCUSSION}

Using a whole-genome sequencing approach, our study sought to identify associations between three different and unexplored classes of DNA variation (pharmacogenetic, CNVs, rare variants) and clozapine-induced myocarditis ${ }^{8}$. Although we did not identify a single robust genetic marker for differentiating cases from controls, we identified 15 novel genes nominally associated with this important and sometimes fatal ADR - which continues to limit the use of clozapine, a highly effective medication for schizophrenia. Among the novel candidate genes identified, 13 were found to be expressed in human myocardium, specifically the ventricular septum, providing biological plausibility of a link between these genes and clozapine-induced myocarditis. Although the mechanisms by which these genes may increase risk for clozapine-induced myocarditis remain unclear and require further 
medRxiv preprint doi: https://doi.org/10.1101/2021.07.26.21261157; this version posted July 29, 2021. The copyright holder for this preprint

272 targets to inform future functional and clinical studies. Such studies may subsequently improve our 273 understanding of the role played by genetic risk of this serious ADR

Our findings add to the list of candidate genes identified in our previous GWAS (GNA15, $A D A M 7, S I X 3, E F H C 1)$ and HLA (HLA-C*07:01) studies of clozapine-induced myocarditis ${ }^{8}$ and suggests that the genetic architecture of this serious ADR is complex and likely polygenic. In fact, each of the candidate genes identified to date have low sensitivity and positive predictive value, limiting their clinical utility. This notion aligns with genomic studies of clozapine-induced agranulocytosis, another rare clozapine ADR, that has been associated with variants from several genes with modest sensitivity (range: $11 \%-36 \%)^{36}$. This current state of the evidence coupled with low incidence of clozapine-induced myocarditis highlights the need for international collaboration to facilitate the rapid ascertainment of cases that will ultimately provide the statistical power required to unravel its complex genetic etiology. Recognizing this need, we formed the PROCLAIM Consortium in 2017 that currently comprises 15 recruitment sites across four countries (Canada, USA, Australia, Turkey $)^{9}$ and are actively looking for new sites to join the consortium.

Our gene enrichment analysis was inconclusive and post hoc exploration of the 15 genes using the published literature showed limited to no associations with phenotypes related to myocarditis, inflammation, or adverse drug reactions with few exceptions (see Supplementary Discussion). However, this is not unsurprising given the lack of previously published genetic studies examining this ADR. One notable exception was neuropeptide Y (NPY), which has a well-established role in modulating cardiac contractibility, protein degradation, and proliferation of cardiomyocytes and has been implicated in the pathogenesis of various cardiovascular morbidities (e.g., cardiac hypertrophy, arrhythmias, heart failure $)^{37}$. Furthermore, clinical associations between $N P Y$ genetic variation and antipsychotic-induced weight gain have been reported ${ }^{38}$. Weight gain and related increases in body mass index (BMI) related to antipsychotic treatment could be clinically relevant given the number of antipsychotic trials patients undergo prior to commencing clozapine and previous work showing high BMI increases clozapine-induced myocarditis fatal outcomes ${ }^{6,39}$. Notably, BMI did not statistically differ between our cases and controls, although there was a trend ( $p=0.107$, Cohen's $d=0.42)$ toward higher BMIs in cases. Given the paucity of genetic markers for clozapine-induced myocarditis, future investigation of rare genetic variation in $N P Y$ and the other 14 putative candidate genes should be considered. 
medRxiv preprint doi: https://doi.org/10.1101/2021.07.26.21261157; this version posted July 29, 2021. The copyright holder for this preprint (which was not certified by peer review) is the author/funder, who has granted medRxiv a license to display the preprint in perpetuity. It is made available under a CC-BY-NC-ND 4.0 International license .

Our findings should be interpreted in the context of notable caveats. Since clozapine-induced myocarditis is a relatively rare event - even despite our international consortium - our patient sample size is small and had suboptimal statistical power to detect small-moderate effect sizes. This was partially mitigated by our demographically-matched case-control design and the deployment of an analysis plan appropriate for small sample sizes. Nevertheless, our results are preliminary and will require independent replication before firm conclusions can be drawn. In addition, functional characterization of the identified genes was limited to existing gene expression data derived from healthy adult human left ventricular septal tissue due to the limited biological material and clinical data available from our study participants. Notably, the PROCLAIM Consortium is currently developing a novel in vitro model using patient-derived induced pluripotent stem cells differentiated into beating cardiomyocytes to understand how clozapine induces myocardial inflammation and to investigate the impact common and rare genetic variants and/or epigenetic modifications have on cardiomyocyte structure and function when exposed to clozapine.

In summary, our whole-genome sequencing analysis identified 15 genes nominally associated with clozapine-induced myocarditis that provide novel candidates for future studies. With the possible exception of $N P Y$, the mechanism by which these genes increase risk for myocarditis is unclear. Although these candidate genes will require independent validation and their roles in the development of clozapine-induced myocarditis remain to be tested, they provide potential insights into the genomic underpinnings and mechanisms by which clozapine induces myocardial inflammation and damage, that may help improve clinical management in the future. 


\section{Acknowledgements}

326 The work was supported in part by the University of Calgary Cumming School of Medicine, Alberta 327 Children's Hospital Research Institute, and University of Melbourne Establishment Grant. P.L is supported by a National Heart Foundation Future Leader Fellowship (102604).

\section{Competing Interests}

$331 \mathrm{CAB}$ is the founder and a shareholder of Sequence2Script Inc and a member of the Clinical Pharmacogenetics Implementation Consortium (CPIC) and Pharmacogene Variation Consortium (PharmVar). The remaining authors declare that the research was conducted in the absence of any commercial or financial relationships that could be construed as a potential conflict of interest.

Author Contributions

$338 \mathrm{CB}$ and $\mathrm{CP}$ conceptualized the study. AN and CB conducted the analyses and wrote the first draft of

339 the manuscript. PL, KR, JM, MJ, NT, RS, DC, RS, SG, and CP contributed to subsequent drafts of the 340 manuscript. All authors approved the final manuscript. 
medRxiv preprint doi: https://doi.org/10.1101/2021.07.26.21261157; this version posted July 29, 2021. The copyright holder for this preprint (which was not certified by peer review) is the author/funder, who has granted medRxiv a license to display the preprint in perpetuity.

\section{References}

1. McGorry P, Killackey, E., Lambert, T., Lambert, M., Jackson, H., Codyre, D., James, N., Pantelis, C., Pirkis, J., Jones, P., Durie, M. A., McGrath, J. J., McGlashan, T., Malla, A., Farhall, J., Herman, H. and Hocking, B. Royal Australian and New Zealand College of Psychiatrists clinical practice guidelines for the treatment of schizophrenia and related disorders. The Australian and New Zealand journal of psychiatry 2005; 39(1-2): 1-30.

2. NICE (2014). Psychosis and schizophrenia in adults: treatment and management. .

3. Siskind D, McCartney L, Goldschlager R, Kisely S. Clozapine v. first- and second-generation antipsychotics in treatment-refractory schizophrenia: systematic review and meta-analysis. $\mathrm{Br} \mathrm{J}$ Psychiatry 2016; 209(5): 385-392.

4. Kilian JG, Kerr K, Lawrence C, Celermajer DS. Myocarditis and cardiomyopathy associated with clozapine. Lancet 1999; 354(9193): 1841-1845.

5. Ronaldson KJ, Fitzgerald PB, McNeil JJ. Clozapine-induced myocarditis, a widely overlooked adverse reaction. Acta Psychiatrica Scandinavica 2015; 132(4): 231-240.

6. Ronaldson KJ, Fitzgerald PB, Taylor AJ, Topliss DJ, Wolfe R, McNeil JJ. Rapid clozapine dose titration and concomitant sodium valproate increase the risk of myocarditis with clozapine: A case-control study. Schizophrenia research 2012; 141(2-3): 173-178.

7. Youssef DL, Narayanan P, Gill N. Incidence and risk factors for clozapine-induced myocarditis and cardiomyopathy at a regional mental health service in Australia. Australas Psychiatry 2016; 24(2): 176180.

8. Lacaze P, Ronaldson KJ, Zhang EJ, Alfirevic A, Shah H, Newman L, et al. Genetic associations with clozapine-induced myocarditis in patients with schizophrenia. Transl Psychiatry 2020; 10(1): 37.

9. Bousman C, Greenway S, Tarailo-Graovac M, Long Q, Sellmer R, Crockford D, et al. The Pharmacogenomics of Clozapine-Induced myocarditis (PROCLAIM) Consortium. . Neuropsychopharmacology 2018: S97-S98.

10. Ronaldson KJ, Fitzgerald PB, Taylor AJ, Topliss DJ, McNeil JJ. A new monitoring protocol for clozapineinduced myocarditis based on an analysis of 75 cases and 94 controls. Aust Nz J Psychiat 2011; 45(6): 458-465.

11. Lee SB, Wheeler MM, Thummel KE, Nickerson DA. Calling Star Alleles With Stargazer in 28 Pharmacogenes With Whole Genome Sequences. Clin Pharmacol Ther 2019; 106(6): 1328-1337.

12. Thorn CF, Müller DJ, Altman RB, Klein TE. PharmGKB summary: clozapine pathway, pharmacokinetics. Pharmacogenet Genomics 2018; 28(9): 214-222.

13. Gaedigk A, Ingelman-Sundberg M, Miller NA, Leeder JS, Whirl-Carrillo M, Klein TE, et al. The Pharmacogene Variation (PharmVar) Consortium: Incorporation of the Human Cytochrome P450 (CYP) Allele Nomenclature Database. Clin Pharmacol Ther 2018; 103(3): 399-401. 
medRxiv preprint doi: https://doi.org/10.1101/2021.07.26.21261157; this version posted July 29, 2021. The copyright holder for this preprint (which was not certified by peer review) is the author/funder, who has granted medRxiv a license to display the preprint in perpetuity.

It is made available under a CC-BY-NC-ND 4.0 International license .

14. Lesche D, Mostafa S, Everall I, Pantelis C, Bousman CA. Impact of CYP1A2, CYP2C19, and CYP2D6 genotype- and phenoconversion-predicted enzyme activity on clozapine exposure and symptom severity. Pharmacogenomics J 2020; 20(2): 192-201.

15. Benjamini $Y$, Hochberg Y. Controlling the false discovery rate: a practical and powerful approach to multiple testing. J R Stat Society Series B (Methodol) 1995; 57: 289-300.

16. Kim JH, Hu HJ, Yim SH, Bae JS, Kim SY, Chung YJ. CNVRuler: a copy number variation-based case-control association analysis tool. Bioinformatics 2012; 28(13): 1790-1792.

17. Larsen SJ, do Canto LM, Rogatto SR, Baumbach J. CoNVaQ: a web tool for copy number variation-based association studies. BMC Genomics 2018; 19(1): 369.

18. Wang K, Li M, Hakonarson H. ANNOVAR: functional annotation of genetic variants from highthroughput sequencing data. Nucleic Acids Res 2010; 38(16): e164.

19. Auton A, Brooks LD, Durbin RM, Garrison EP, Kang HM, Korbel JO, et al. A global reference for human genetic variation. Nature 2015; 526(7571): 68-74.

20. Fu W, O'Connor TD, Jun G, Kang HM, Abecasis G, Leal SM, et al. Analysis of 6,515 exomes reveals the recent origin of most human protein-coding variants. Nature 2013; 493(7431): 216-220.

21. Karczewski KJ, Weisburd B, Thomas B, Solomonson M, Ruderfer DM, Kavanagh D, et al. The ExAC browser: displaying reference data information from over 60000 exomes. Nucleic Acids Res 2017; 45(D1): D840-D845.

22. Drmanac R, Sparks AB, Callow MJ, Halpern AL, Burns NL, Kermani BG, et al. Human genome sequencing using unchained base reads on self-assembling DNA nanoarrays. Science 2010; 327(5961): 78-81.

23. Karczewski KJ, Francioli LC, Tiao G, Cummings BB, Alföldi J, Wang Q, et al. The mutational constraint spectrum quantified from variation in 141,456 humans. Nature 2020; 581(7809): 434-443.

24. Li H. A statistical framework for SNP calling, mutation discovery, association mapping and population genetical parameter estimation from sequencing data. Bioinformatics 2011; 27(21): 2987-2993.

25. Zhan X, Hu Y, Li B, Abecasis GR, Liu DJ. RVTESTS: an efficient and comprehensive tool for rare variant association analysis using sequence data. Bioinformatics 2016; 32(9): 1423-1426.

26. Guo MH, Plummer L, Chan YM, Hirschhorn JN, Lippincott MF. Burden Testing of Rare Variants Identified through Exome Sequencing via Publicly Available Control Data. Am J Hum Genet 2018; 103(4): 522-534.

27. Petrovski S, Wang Q, Heinzen EL, Allen AS, Goldstein DB. Genic intolerance to functional variation and the interpretation of personal genomes. PLoS Genet 2013; 9(8): e1003709. 
medRxiv preprint doi: https://doi.org/10.1101/2021.07.26.21261157; this version posted July 29, 2021. The copyright holder for this preprint (which was not certified by peer review) is the author/funder, who has granted medRxiv a license to display the preprint in perpetuity.

It is made available under a CC-BY-NC-ND 4.0 International license .

28. Petrovski S, Gussow AB, Wang Q, Halvorsen $M$, Han $Y$, Weir WH, et al. The Intolerance of Regulatory Sequence to Genetic Variation Predicts Gene Dosage Sensitivity. PLoS Genet 2015; 11(9): e1005492.

29. Chen J, Bardes EE, Aronow BJ, Jegga AG. ToppGene Suite for gene list enrichment analysis and candidate gene prioritization. Nucleic Acids Res 2009; 37(Web Server issue): W305-311.

30. Hahn V, Knutsdottir H, Luo X, Bedi K, Margulies K, Haldar S, ., et al. Myocardial gene expression signatures in human heart failure with preserved ejection fraction. Zenodo Data Repository 2020.

31. Hahn V, Knutsdottir H, Luo X, Bedi K, Margulies K, Haldar S, ., et al (2020). Myocardial gene expression signatures in human heart failure with preserved ejection fraction: Zenodo Data Repository.

32. Love MI, Huber W, Anders S. Moderated estimation of fold change and dispersion for RNA-seq data with DESeq2. Genome Biol 2014; 15(12): 550.

33. Health Canada (2020). Clozapine Product Monograph. Health Canada: Ottawa.

34. ACSQHC (2012). National Adult Clozapine Titration Chart User Guide. Australian Commission on Safety and Quality in Health Care Sydney.

35. NHS (2019). CLOZAPINE TREATMENT GUIDELINES. National Health Service Foundation Trust: United Kingdom.

36. Legge SE, Walters JT. Genetics of clozapine-associated neutropenia: recent advances, challenges and future perspective. Pharmacogenomics 2019; 20(4): 279-290.

37. Tan CMJ, Green P, Tapoulal N, Lewandowski AJ, Leeson P, Herring N. The Role of Neuropeptide $\mathrm{Y}$ in Cardiovascular Health and Disease. Front Physiol 2018; 9: 1281.

38. Shams TA, Müller DJ. Antipsychotic induced weight gain: genetics, epigenetics, and biomarkers reviewed. Curr Psychiatry Rep 2014; 16(10): 473.

39. Ronaldson KJ, Fitzgerald PB, Taylor AJ, Topliss DJ, McNeil JJ. Clinical course and analysis of ten fatal cases of clozapine-induced myocarditis and comparison with 66 surviving cases. Schizophrenia research 2011; 128(1-3): 161-165. 
medRxiv preprint doi: https://doi.org/10.1101/2021.07.26.21261157; this version posted July 29, 2021. The copyright holder for this preprint (which was not certified by peer review) is the author/funder, who has granted medRxiv a license to display the preprint in perpetuity. It is made available under a CC-BY-NC-ND 4.0 International license .

\section{$474 \quad$ Figure Legends}

Figure 1. PROCLAIM study design, analysis and key results. Age, sex and ethnicity matched treatment resistant schizophrenia patients who did (cases) or did not (controls) develop myocarditis following clozapine exposure were recruited. Using whole genome sequencing data, candidate pharmacogenetic variants, copy number variable regions and rare variants were examined for their association with clozapine-induced myocarditis.

Figure 2. Distribution of titration slopes by history of clozapine-induced myocarditis. Cases differed significantly from controls $(\mathrm{p}=0.006)$. Dashed lines represent titration slopes recommended by clozapine dosing protocols in Canada, United Kingdom, and Australia. Case titration slopes did not differ from slopes recommended by protocols used in Canada ( $p=0.544$, United Kingdom $(p=0.795)$, or Australia ( $\mathrm{p}=0.259)$. Likewise, control titration slopes did not differ from slopes recommended by protocols used in Canada $(\mathrm{p}=0.187$, United Kingdom $(\mathrm{p}=0.248)$, or Australia $(\mathrm{p}=0.869)$.

Figure 3. Normalised RNASeq read counts of the 15 nominally associated loci identified in gene burden analysis in left ventricular septal tissue of healthy adult donors $(\mathrm{n}=21)$. MLLT6: PHD Finger Containing, CADPS: Calcium Dependent Secretion Activator, TACC2: Transforming Acidic CoiledCoil Containing Protein 2, L3MBTL4: L3MBTL Histone Methyl-Lysine Binding Protein 4, NPY: Neuropeptide Y, SLC25A21: Solute Carrier Family 25 Member 21, PARVB: Parvin Beta, GPR179: G Protein-Coupled Receptor 179, ACAD9: Acyl-CoA Dehydrogenase Family Member 9, NOL8: Nucleolar Protein 8, NADK2: NAD Kinase 2, Mitochondrial, FAM172A: Family With Sequence Similarity 172 Member A, AFDN: Afadin, Adherens Junction Formation Factor, SLC6A11: Solute Carrier Family 6 Member 11, PXDN: Peroxidasin 
medRxiv preprint doi: https://doi.org/10.1101/2021.07.26.21261157; this version posted July 29, 2021. The copyright holder for this preprint (which was not certified by peer review) is the author/funder, who has granted medRxiv a license to display the preprint in perpetuity.

It is made available under a CC-BY-NC-ND 4.0 International license.

Table 1. Demographic and clinical characteristics of participants with $(\mathrm{N}=25)$ and without $(\mathrm{N}=25)$ a history of clozapine-induced myocarditis

\section{Characteristic}

Age, mean (sd) years

Sex, n (\%) males

Self-Report Ancestry ${ }^{\mathrm{a}}$, n (\%)

European

East Asian

South Asian

Near Eastern

Oceanian

Body mass index, mean (sd)

Highest dose received in first 28 days, mean (sd)

Titration slope ${ }^{\mathrm{b}}$, mean (sd)

Days from clozapine initiation to myocarditis, mean (sd)

Valproic acid use, n (\%)

Concomitantly used inhibitors, n (\%)

CYP1A2 inhibitor ${ }^{\mathrm{C}}$

CYP2C9 inhibitor ${ }^{\mathrm{c}}$

CYP2C19 inhibitor ${ }^{\mathrm{c}}$

CYP2D6 inhibitor ${ }^{\mathrm{c}}$

CYP2E1 inhibitor ${ }^{\mathrm{c}}$

CYP3A4/5 inhibitor ${ }^{\mathrm{c}}$
Clozapine-induced myocarditis

$36(13)$
$18(72 \%)$

$21(84 \%)$

$2(8 \%)$

$0(0 \%)$

$1(4 \%)$

$1(4 \%)$

31 (10)

$274(84)$

$20(8)$

$15(5)$

$6(25 \%)$

$$
0(0 \%)
$$

$0(0 \%)$

$2(8 \%)$

$5(20 \%)$

$0(0 \%)$

$0(0 \%)$
Clozapinetolerant controls

$35(11)$

$19(76 \%)$

0.650

0.747

0.695

$20(80 \%)$

$3(12 \%)$

$1(4 \%)$

$1(4 \%)$

$0(0 \%)$

$27(9)$

0.107

310 (150)

0.366

14 (6)

0.006

$8(32 \%) \quad 0.588$

$0(0 \%)$

1.000

$0(0 \%)$

1.000

$2(8 \%) \quad 1.000$

$6(24 \%) \quad 0.733$

$0(0 \%) \quad 1.000$

$0(0 \%) \quad 1.000$

Concomitantly used inducers, $\mathrm{n}(\%)$

Tobacco (smoked)

$6(26 \%)$

$10(40 \%)$

0.307

Carbamazepine

$0(0 \%)$

$1(4 \%) \quad 0.312$

${ }^{a}$ Ancestry groupings are based on the biogeographic grouping system described by Huddart et al., Clin Pharmacol Ther. 2019, 105(5): 1256-1262.

${ }^{\mathrm{b}}$ Slope $=($ highest dose in first 28 days - starting dose $) /($ days of titration -1$)$. A higher slope translates to a faster titration.

${ }^{c}$ Medications taken by participants that are known to be moderate or strong inhibitors of CYP1A2, CYP2C19, CYP2C19, CYP2D6, CYP2E1 or CYP3A4/5 according to the Flockhart Drug Interactions Table (https://drug-interactions.medicine.iu.edu/Main-Table.aspx) 


\begin{tabular}{|c|c|c|c|c|c|c|c|c|c|}
\hline \multirow[b]{2}{*}{ Genes } & \multirow[b]{2}{*}{$\begin{array}{r}\text { Frequency } \\
\text { Controls } \\
(n=24)\end{array}$} & \multirow[b]{2}{*}{$\begin{array}{r}\text { Frequency } \\
\text { Cases } \\
(n=25)\end{array}$} & \multirow[b]{2}{*}{$\begin{array}{r}\text { Frequency } \\
\text { gnomAD } \\
(n=15,708)\end{array}$} & \multicolumn{3}{|c|}{ Case vs Control } & \multicolumn{2}{|c|}{ Two Proportion Z-test } & \multirow[b]{2}{*}{$\begin{array}{r}\text { RVIS } \\
\text { (Percentile) }^{\mathbf{1}}\end{array}$} \\
\hline & & & & $\begin{array}{r}\text { CMC } \\
\text { P-value }\end{array}$ & $\begin{array}{l}\text { SKAT-O } \\
\text { P-value }\end{array}$ & $\begin{array}{r}\text { Empirical } \\
\text { P-value }\end{array}$ & $\begin{array}{r}\text { Case vs } \\
\text { gnomAD } \\
\text { P-value }\end{array}$ & $\begin{array}{r}\text { Control vs } \\
\text { gnomAD } \\
\text { P-value }\end{array}$ & \\
\hline MLLT6 & 0.000 & 0.140 & 0.007 & 0.0051 & 0.0324 & 0.0042 & $3.9 \times 10^{-15} *$ & 0.6818 & $-1.51(6.0 \%)$ \\
\hline CADPS & 0.000 & 0.120 & 0.025 & 0.0104 & 0.0207 & 0.0101 & $0.0024^{*}$ & 0.4354 & $-2.30(2.2 \%)$ \\
\hline TACC2 & 0.021 & 0.160 & 0.024 & 0.0119 & 0.0500 & 0.0103 & $9.9 \times 10^{-6} *$ & 0.9203 & $1.92(96.5 \%)$ \\
\hline L3MBTL4 & 0.000 & 0.100 & 0.007 & 0.0208 & 0.0354 & 0.0198 & $3.5 \times 10^{-8} *$ & 0.6818 & $0.38(66.9 \%)$ \\
\hline NPY & 0.000 & 0.100 & 0.032 & 0.0208 & 0.0208 & 0.0208 & 0.0539 & 0.3735 & $-0.08(45.5 \%)$ \\
\hline SLC25A21 & 0.021 & 0.140 & 0.037 & 0.0240 & 0.0344 & 0.0209 & 0.0065 & 0.6745 & $0.51(72.2 \%)$ \\
\hline PARVB & 0.000 & 0.100 & 0.025 & 0.0208 & 0.0445 & 0.0211 & 0.0166 & 0.4354 & $0.29(62.8 \%)$ \\
\hline GPR179 & 0.000 & 0.100 & 0.039 & 0.0208 & 0.0399 & 0.0218 & 0.1158 & 0.3222 & $2.80(98.9 \%)$ \\
\hline ACAD9 & 0.000 & 0.100 & 0.028 & 0.0208 & 0.0491 & 0.0218 & 0.0295 & 0.4056 & $-0.69(21.3 \%)$ \\
\hline NOL8 & 0.000 & 0.100 & 0.049 & 0.0208 & 0.0491 & 0.0221 & 0.2382 & 0.2670 & $1.92(96.5 \%)$ \\
\hline NADK2 & 0.000 & 0.100 & 0.015 & 0.0208 & 0.0491 & 0.0222 & $0.0005^{*}$ & 0.5485 & $0.30(63.4 \%)$ \\
\hline FAM172A & 0.021 & 0.140 & 0.016 & 0.0240 & 0.0457 & 0.0225 & $9.2 \times 10^{-7} *$ & 0.8145 & $-0.38(32.2 \%)$ \\
\hline AFDN & 0.000 & 0.100 & 0.017 & 0.0208 & 0.0208 & 0.0227 & $0.0013^{*}$ & 0.5222 & $-1.65(5.0 \%)$ \\
\hline SLC6A11 & 0.000 & 0.120 & 0.029 & 0.0208 & 0.0292 & 0.0239 & 0.0068 & 0.3953 & $-0.71(20.7 \%)$ \\
\hline PXDN & 0.000 & 0.100 & 0.009 & 0.0208 & 0.0399 & 0.0253 & 0.0348 & 0.6384 & $-1.08(11.4 \%)$ \\
\hline
\end{tabular}

507 Comparing frequency of qualifying rare and deleterious variants per gene between cases and controls in the PROCLAIM cohort.

508 Frequencies of the qualifying rare variants in cases and controls were also compared with public controls (gnomAD v2 public

509 database).

$510 *$ significant after Bonferroni correction (0.05/15 tests $=0.0033) .1$ = RVIS Score, a gene-based gene intolerance score based on ExAC

511 v2 release. Genes with negative scores are more "intolerant" then those with positive scores. MLLT6: PHD Finger Containing,

512 CADPS: Calcium Dependent Secretion Activator, TACC2: Transforming Acidic Coiled-Coil Containing Protein 2, L3MBTL4:

513 L3MBTL Histone Methyl-Lysine Binding Protein 4, NPY: Neuropeptide Y, SLC25A21: Solute Carrier Family 25 Member 21,

514 PARVB: Parvin Beta, GPR179: G Protein-Coupled Receptor 179, ACAD9: Acyl-CoA Dehydrogenase Family Member 9, NOL8:

515 Nucleolar Protein 8, NADK2: NAD Kinase 2, Mitochondrial, FAM172A: Family With Sequence Similarity 172 Member A, AFDN:

516 Afadin, Adherens Junction Formation Factor, SLC6A11: Solute Carrier Family 6 Member 11, PXDN: Peroxidas 
medRxiv preprint doi: https://doi.org/10.1101/2021.07.26.21261157; this version posted July 29, 2021. The copyright holder for this preprint (which was not certified by peer review) is the author/funder, who has granted medRxiv a license to display the preprint in perpetuity.

\author{
It is made available under a CC-BY-NC-ND 4.0 International license.
}




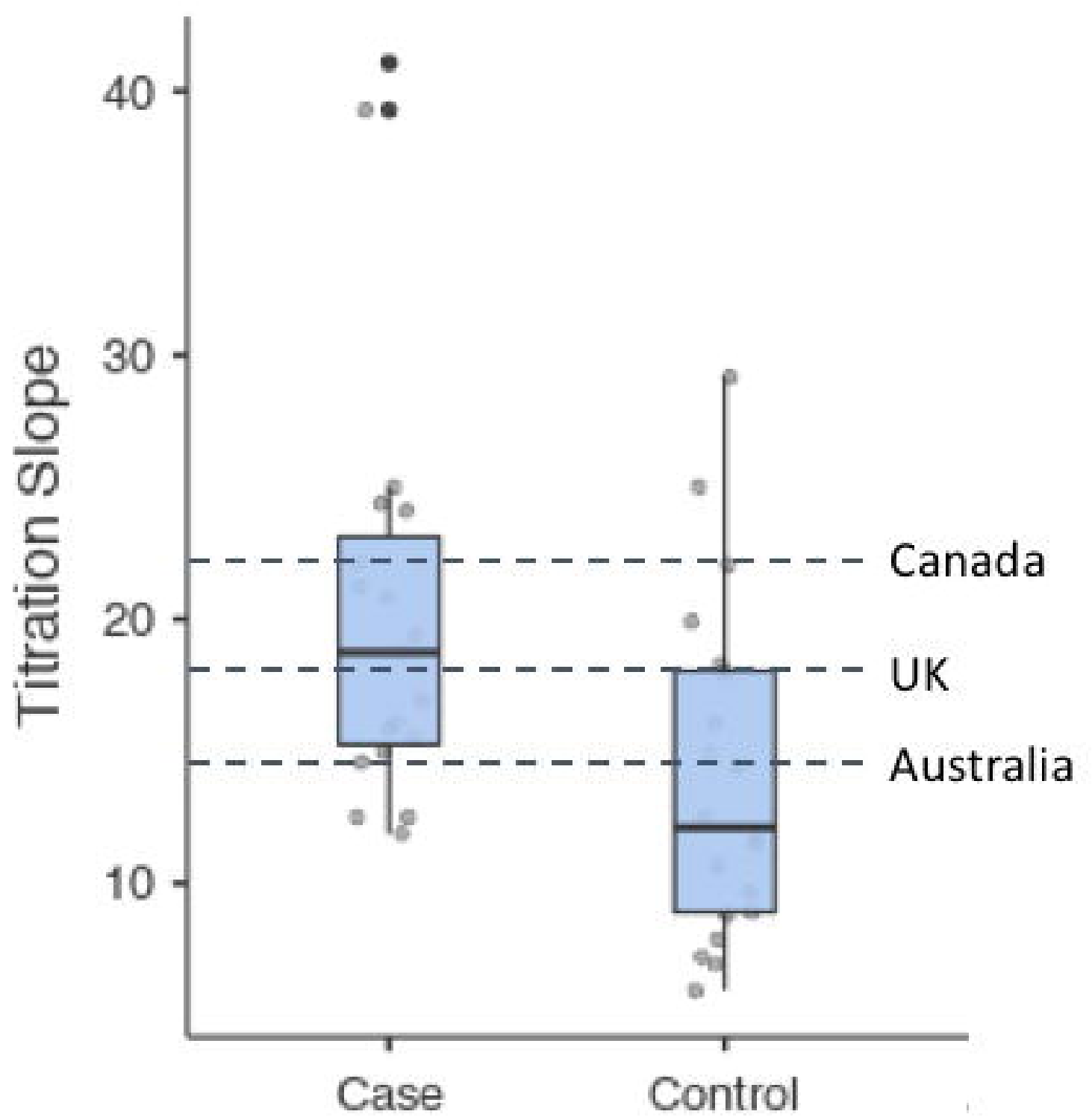




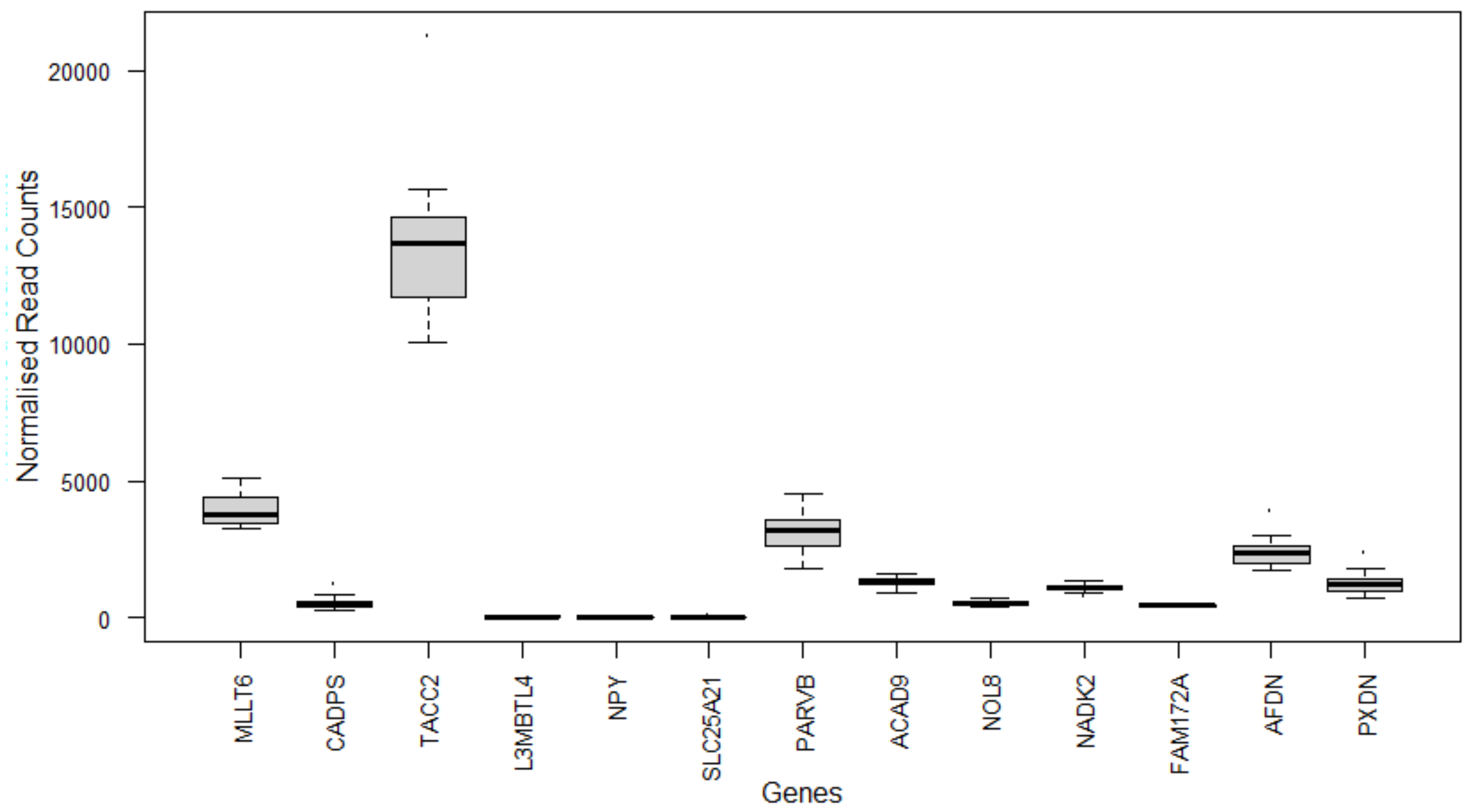

